\title{
A Quality of Life Framework for Special Education Outcomes
}

\author{
H. RUTHERFORD TURNBULL 11, ANN P. TURNBULL, MICHAEL L. WEHMEYER,
} AND JIYEON PARK

\section{ABSTRACT}

The national goals of higher expectations for all students and their emphasis on academic achievement are reviewed in light of the data on outcomes for students with disabilities. A new framework for measuring outcomes along the lines of quality of life is proposed. The framework regards academic goals as the means for achieving other outcomes, namely the four outcomes that the Individuals with Disabilities Education Act (IDEA) declared: equality of opportunity, full participation, independent living, and economic self-sufficiency. We propose that the underlying goal of education should be to enhance the quality of life of students with disabilities and that the four overarching IDEA goals, as implemented in part by the emphasis on academic achievement, should guide the curriculum and all assessment measures.

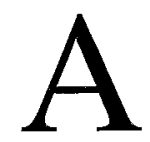

DISTINGUISHING CHARACTERISTIC OF GENeral and special education today is the emphasis on outcomes. Nowhere is this emphasis more directly expressed than in the report of the President's Commission on Excellence in Special Education (2002). The prevailing mechanisms for achieving outcomes involve the establishment of educational standards and the implementation of procedures designed to ensure student attainment of those standards. There are typically two types of standards:

1. Content standards define the knowledge skills and understanding that students should acquire in academic areas.
2. Performance standards define the levels of achievement in academic subjects that students must meet to prove their proficiency.

Neither type of standard is apt to be met unless teachers use evidence-based, scientifically validated instructional techniques. State and district assessments of student performance measure students' proficiency in both content and performance standards; student performance is the outcome (Thurlow, 2000). More than that, however, student performance determines consequences for students (graduation and grade promotion), teachers and principals (promotion, salary increases, and job retention), and schools and school districts (accreditation, funding, and federal assistance under the No Child Left Behind Act).

Partly because special education has for so long operated under a federally mandated accountability system that emphasized compliance with legally codified processes, students with disabilities have for the most part been omitted from the general education accountability system; indeed, many have been omitted from the general education curriculum, in part because they are apt to perform less well than other students. The 1997 amendments to the Individuals 'with Disabilities Education Act (IDEA) provided for greater student access to the general education curriculum and for their participation in state and district assessments. The degree to which access and outcomes are achieved is under scrutiny, especially in the report of the President's Commission on 
Excellence in Special Education (2002) and in a seminal critique of special education (Finn et al., 2001).

In light of the 1997 IDEA amendments and the debate about the outcomes of special education, it is important to bear in mind the underpinnings of the IDEA mandate for access to the general education curriculum and the implications of standards-based reform for students with disabilities in regard to the original intent of IDEA. There has, to this point, been insufficient consideration of these issues. The purpose of this article is to take a serious look at IDEA with regard to its original and continuing intent and to focus on the global outcome of quality of life for students with disabilities and their families. This focus does not assert that academic outcomes are unimportant; indeed, they are quite important, and measuring them is necessary but not sufficient if special educators and their allies in general education intend to be serious about outcomes. But this new kind of focus on the more global outcomes, and on academic performance as a surrogate measure for the more global outcomes, raises issues that have not been part of the discussion concerning the education of students with disabilities, IDEA, and school reform.

\section{IDEA And Access to the General CURRICULUM}

It is undoubtedly worthwhile to align the education of students with disabilities with the standards-based reform movement through access to the general education curriculum and to raise expectations for these students, which often reflect negative stereotypes of disability and resulting biases against their participation in the general education curriculum and state and district assessments (Wehmeyer, Lattin, \& Agran, 2001; Wehmeyer, Sands, Knowlton, \& Kozleski, 2002). That is why the Individualized Education Programs (IEPs) of students with disabilities should provide for access to the general education curriculum and why teacher competence is such an important issue. But the lack of clarity and specificity for defining the general education curriculum and the largely unacknowledged conflicts between the original intent of IDEA and certain (though not all) aspects of standards-based reform are problematic.

1. Neither IDEA nor its regulations define the term general education curriculum other than to say it is "the same curriculum as for nondisabled children" (Federal Register, 1999, p. 12592). Given that (a) the stated purpose of standardsbased reform seems to be to narrow the curriculum to core academic content areas (the No Child Left Behind Act); (b) most states have developed standards primarily or exclusively in core academic content areas; (c) in most states, the statewide assessment tests only core academic content; and (d) most states hold educators and schools accountable only for student performance on standardized state tests, it seems that the general education curriculum becomes only the core academic curriculum and, accordingly, fails to provide the scope and content needed to ensure positive outcomes for all students, including students with severe cognitive or multiple disabilities.

2. The current results-oriented discourse (including the No Child Left Behind Act) fails to take into account the outcomes that are critical in the lives of many students with and without disabilities, including outcomes focused on such important adult areas as employment and independent living. Despite rhetoric to the contrary, the results that matter in the current reform climate are standardized test results.

3. There are few data concerning the impact of statewide or high-stakes testing on students with disabilities and other students who perform poorly on standardized assessments, including students. from low socioeconomic status communities or from racial and ethnic groups that are often overrepresented in those communities and in special education. Moreover, federally initiated examinations of the performance of students with disabilities in statewide, standardized tests by the President's Commission on Excellence in Special Education reach remarkably similar conclusions: (a) little is known about the impact of using standards-based reform to drive educational reform for students with disabilities, and (b) the risks inherent in combining standards with high-stakes testing for this population are evident and potentially quite harmful.

4. The establishment of high-stakes consequences for students based on their performance on statewide tests assumes that the threat of failing to achieve desired outcomessuch as a high school diploma or promotion to the next grade-will motivate students to study or work harder. It is an equally valid hypothesis that students who do not succeed in the realm of standardized assessments may, in fact, be differentially motivated to leave school.

There is no doubt that the special education field is well along the way of implementing the IDEA access mandates. The most recent data indicate that approximately two thirds of students with disabilities are participating in statewide assessments (Thurlow, 2000). There is much to praise about a demand for high expectations for all students and a focus on aligning the curriculum to meet those expectations. If, however, the field does not, to paraphrase Pasternak (2002), take a hard look at how standards-based reform is affecting students with disabilities, there is a risk of leaving some children behind. Issues of access and outcomes need to be considered in light of the four primary purposes of the IDEA, or else the No Child Left Behind Act will be an empty law for students with disabilities.

\section{Moving Beyond Academics}

Clearly, standards-based reform seeks to reduce the curriculum to core academic areas. An emphasis on academic outcomes alone, however, runs counter to the intent of the IDEA, as demonstrated in a model of desired and appropriate edu- 
cational outcomes developed by the National Center on Education Outcomes (NCOE) in the early 1990s. Based on broad input from stakeholders, NCEO identified eight domains of viable IDEA outcomes: (a) presence and participation, (b) accommodation and adaptation, (c) physical health, (d) social/ emotional adjustment, (e) independence and responsibility, (f) contribution and citizenship, (g) satisfaction, and (h) academic and functional literacy (Ysseldyke et al., 1998).

Notably, academics is only one of eight domains. What happened to the other seven domains? Arguably, they are critically important for the success of all students, with and without disabilities, during elementary, secondary, and postsecondary years.

Against the backdrop of standards-based reform, what guidance does IDEA provide? How does it balance its goals with the content and performance standards of standardsbased reform and high-stakes testing? IDEA sends double but nonetheless mutually consistent messages in (a) its expectations that students will have access to and will make progress in the general education curriculum and (b) its four goals for students with disabilities-equality of opportunity, full participation, independent living, and economic self-sufficiency.

On the one hand, IDEA ensures access to and progress in the general education curriculum through the following IEP-required components (20 U.S.C. § 1414(d)):

1. The student's present levels of educational performance, including

- how the disability of the student (ages 6 through 21) affects his or her involvement and progress in the general education curriculum.

2. Measurable annual goals, including benchmarks or short-term objectives related to

- meeting needs resulting from the disability, in order to enable the student to be involved in and progress in the general education curriculum.

3. The special education and related services and supplementary aids and services that will be provided to the student or on the student's behalf and the program modifications or supports for school personnel that will be provided so that the student can

- be involved in and progress through the general education curriculum and participate in extracurricular and other nonacademic activities and

- be educated and participate with other students with disabilities and with students who do not have disabilities in general education.
These requirements are the means for improving student achievement in traditional curriculum areas.

On the other hand, IDEA's goals are far broader than academic content and, we contend, the general education curriculum needs to be defined much more broadly than only by academic content. Because IDEA outcome goals are in the national declaration of Congressional policy, they should be interpreted in at least two ways: first, as the primary guide to students' curriculum, and second, as the overarching statement of desired and to-be-measured outcomes.

With respect to students' curriculum, IDEA provides that - the education of students with disabilities can be made more effective by ensuring that all personnel (note the word all, which includes general and special educators alike) should benefit from personnel development to ensure that they will have the skills to enable students to "be prepared to live productive, independent adult lives, to the maximum extent possible" (20 U.S.C. $\$ 1400$ (c)(5)(E)(ii)). Accordingly, state and district administrators concerned with outcome-driven results should understand that students' outcomes of being able to be productive and to live independently are goals that must be adopted and that school and student performance concerning them must be measured. Likewise, when IDEA provides that its purpose is to ensure that all students with disabilities receive an education that prepares them "for employment and independent living" (20 U.S.C. $\S 1400$ (c)(5)(E)), the same requirement obtains: education that leads to work and independent living is a curriculum goal that must be implemented and evaluated.

\section{Defining the Four IDEA Goals}

Just what does each of the four IDEA goals mean? The answer comes in part from IDEA and in part from three other federal disability statutes: (a) the Americans with Disabilities Act (ADA) of 1990; (b) the Rehabilitation Act of 1973; and (c) the Developmental Disabilities Assistance and Bill of Rights Act (DDABRA) of 2000. In their analysis of these three statutes, H. R. Turnbull and his colleagues have determined that these statutes and IDEA reflect the core concepts of disability policy (H. R. Turnbull, Beegle, \& Stowe, 2001; H. R. Turnbull, Wilcox, Stowe, \& Umbarger, 2001). Their analysis provides meaning to IDEA's four outcomes.

1. Equal opportunity is grounded in the nation's policy to prohibit discrimination. Antidiscrimination means (a) not discriminating against a person solely because of the person's disability and (b) providing reasonable accommodations so the person can participate in a program. In education, some students who are not eligible under IDEA (e.g., students with attention-deficit/hyperactivity disorder) are protected under Section 504 of the Rehabilitation Act (antidiscrimination provision).

2. Full participation derives from the policy to ensure integration and prohibit segregation. Integration refers to the 
right of a person with a disability to (a) not be segregated solely on the basis of disability from persons who do not have disabilities, (b) not be barred from participating in services that benefit persons who do not have disabilities, and (c) not be limited to participating in services that are exclusively for people with disabilities. Under IDEA, the integration principle is carried out through access to the general education curriculum and the requirement for placement in the least restrictive setting.

3. Independent living involves the core concepts of antidiscrimination and integration, but it also involves the core concepts of empowerment, participatory decision making, and autonomy. Empowerment and participatory decision making refer to the right of a person with a disability or the person's representatives to have a say in what happens to the person. Under IDEA, the student's parents, and the student when appropriate, have the right to participate in the development and implementation of the student's IEP. Autonomy refers to the right of a person or the person's representatives to consent, refuse to consent, or otherwise control or exercise choice over what happens to the person. Under IDEA, the student's parents, or the student at the age of majority, have the right to consent or object to classification, program, and placement options. Likewise, under the Rehabilitation Act, a person with a disability has the right to make choices about how to live in the community and about the supports necessary to live in the community. The choice about where and how to live is the statutory expression of the concept quality of life: Choosing how to live is choosing one's quality of life.

4. Finally, economic self-sufficiency refers to the core concept of productivity. Productivity refers to engagement in (a) income-producing work or (b) unpaid work that contributes to a household or community. Under IDEA, the transition components of the IEP provisions ensure consideration of employment options for the student from age 14 forward.

Given that IDEA clearly sets forth these four goals, it is disconcerting that they have been largely overlooked in the national dialogue related to outcomes. This omission is especially problematic given the postsecondary outcomes related to these goals. Relative to people without disabilities, individuals with disabilities still experience higher rates of unemployment and underemployment, higher dropout rates and lower rates of postsecondary school enrollment, more restricted participation in community and leisure time activities, more dependency on parents and federal or state cash transfer programs, and significantly lower rates of home ownership (Browning, Dunn, Rabren, \& Whetstone, 1995; Fabian, Lent, \& Willis, 1998; National Center for Education Statistics, 2000; Ross, 1996).

Outcomes for students with disabilities from culturally and linguistically diverse backgrounds are even more dismal. Hispanic youths have significantly lower rates of employment than their White peers (Blackorby \& Wagner, 1996). African American men are much less likely than their White peers to be employed 3 and 5 years after high school (Black- orby \& Wagner, 1996). Males from diverse racial backgrounds (especially urban communities and low-income homes) have the highest dropout rate (National Center for Education Statistics, 2000).

\section{LINKING IDEA GOALS TO QUALITY OF LIFE OUTCOMES}

Although it is rare to see the four specific IDEA goals stated as educational outcomes in the special education literature, it is not unusual to see the summary phrases quality of life or lifestyle change as a stated outcome of education. For example, over the last 10 years, a rich literature has developed related to self-determination and interventions to foster selfdetermination as an element of a student's quality of life. As early as 1985, A. P. Turnbull and Turnbull (1985) argued that independence is "a fundamental value in our society" and defined independence as "choosing how to live one's own life within one's inherent capabilities and means and consistent with one's personal values and preferences" (p. 108). They then said that independence "is synonymous with freedom of choice, self-determination, and autonomy from outside interference. Independence is the converse of being obliged to live one's life as others want that life to be lived" (p. 108). More recently, Wehmeyer defined self-determined behavior as "acting as the primary causal agent in one's life and making choices and decisions regarding one's quality of life [italics added] free from undue external influence or interference" (Wehmeyer, 1996, p. 22). Adults with mental retardation who report a higher quality of life are also identified as being more self-determined (Wehmeyer \& Schwartz, 1998; Wehmeyer \& Schalock, 2001). Likewise, researchers in positive behavior support have argued that the result of such supports is not just the elimination of problem behavior but also the enhancement of quality of life (Carr et al., 1999; Horner et al., 1990). Similarly, almost a decade ago, Halpern (1993) called for a quality of life framework for evaluating transition results. And positioning quality of life into a public policy framework is neither new (H. R. Turnbull \& Brunk, 1997) nor conceptually difficult (H. R. Turnbull \& Stowe, 2001). To lay the groundwork for operationalizing IDEA's four goals in a quality of life framework, it is helpful to know the literature about quality of life definitions, domain conceptualizations, and measurement. Only then are the implications for the IDEA reauthorization, research, and practice made clear.

\section{Defining and Measuring Quality of Life}

Quality of life has no single uniform definition (O'Boyle, 1997). Cummins (1997) summarized 60 quality of life definitions. Hughes and Hwang (1996) analyzed 87 studies on what constitutes'quality of life and identified 44 definitions. A group of international researchers who have done primary research 
on quality of life in the field of intellectual disabilities developed a consensus related to the conceptualization measurement and application of quality of life (The Special Interest Research Group on Quality of Life, 2000). They underscored that the key characteristics of all definitions are (a) general feelings of well-being, (b) feelings of positive social involvement, and (c) opportunities to achieve personal potential. Indeed, researchers have agreed that quality of life is multidimensional and includes both subjective and objective dimensions (Halpern, 1993; The Special Interest Research Group on Quality of Life, 2000; Testa \& Simonson, 1996).

\section{Conceptualizing Quality of Life Domains}

Not surprisingly, each research study on quality of life has its own framework. For example, Felce (1997) presented six categories: physical, material, social, emotional, productive, and civic well-being. Schalock (1996) proposed eight domains: emotional well-being, interpersonal relations, material well-being, personal development, physical well-being, selfdetermination, social inclusion, and rights. An international group of researchers (Schalock et al., 2002) adopted Schalock's eight domains and specified subdomains as follows:

- Emotional well-being: safety, stable and predictable environments, positive feedback

- Interpersonal relations: affiliations, affection, intimacy, friendships, interactions

- Material well-being: ownership, possessions, employment

- Personal development: education and habilitation, purposive activities, assistive technology

- Physical well-being: health care, mobility, wellness, nutrition

- Self-determination: choices, personal control, decisions, personal goals

- Social inclusion: natural supports, integrated environments, participation

- Rights: privacy, ownership, due process, barrier-free environments. (The Special Interest Research Group on Quality of Life, 2000, p. 28)

\section{Measuring Quality of Life}

It is difficult to measure quality of life, but

- Almost all measurement tools have multiple domains, with multiple items in each domain.
- A variety of measurement methods have been used for assessing quality of life for persons with disabilities, including surveys and questionnaires (e.g., Cummins, McCabe, Romeo, \& Gullone, 1994; Ferrans \& Powers, 1985), interviews (e.g., Lehman, 1988), vicarious interviews, and vicarious surveys (e.g., Johnson \& Cocks, 1989; OuelletteKuntz \& McCreary, 1996). Most developers invested efforts to involve the persons with disabilities, but usually they depended on a vicarious response. In some tools, parents or siblings were the major vicarious respondents for the measurement (e.g., Becker, Diamond, \& Sainfort, 1993; Ouellette-Kuntz \& McCreary, 1996).

- Very few of the measurement tools considered separate versions for persons with disabilities in different life stages (e.g., Cummins et al., 1994; Keith \& Schalock, 1994; Timmons, 1993). Therefore, some items were not applicable to certain groups of individuals (e.g., asking about job satisfaction to junior high school students).

Subjectivity Versus Objectivity. Although quality of life is defined using a combination of both, the matter of its subjectivity or objectivity is controversial (Halpern, 1993). Because the measurement of intervention results depends on how the results (i.e., quality of life) are conceptualized, this controversy is not unexpected and deserves careful attention.

Those who argue for the objective conceptualization of quality of life maintain that quality of life is the sum of the objectively measurable life conditions experienced by an individual. They contend that subjective satisfaction is nothing more than the response to those conditions (Stark \& Goldsbury, 1990). Others argue that a person's expressed satisfaction with life is the dispositive criterion because each individual or family differs in what they enjoy, desire from life, or find important (Edgerton, 1990; Gill \& Feinstein, 1994; O'Boyle, 1997; Taylor \& Bogdan, 1990). Some researchers accommodate both perspectives (Bradley \& Knoll, 1990; Conroy \& Feinstein, 1990; Felce, 1997; Schalock, Keith, Hoffman, \& Karen, 1989; Stainback \& Stainback, 1989). For example, Schalock (2000) suggested that some domains and indicators (e.g., emotional well-being) are more amenable to personal appraisal, whereas others (e.g., material well-being) are better suited to objective assessment.

The Uniqueness of Each Individual. The uniqueness of each individual is at the heart of how quality of life should be measured when individuals are so highly diverse. At the individual level, a prominent measurement consideration may be whether the person has a disability or not. Schalock 
(2000) argued that quality of life for persons with disabilities encompasses the same indicators that are important to persons without disabilities. On the other hand, Hatton (1998) asserted that the experiences of persons with disabilities can be restricted because of the limits imposed by disability conditions; and these limited experiences, in turn, may result in different indicators of quality of life. Accordingly, specific attention should be paid to the uniqueness of each individual in conceptualizing and constructing a valid measurement for quality of life (Borthwick-Duffy, 1996).

\section{Quality of Life and Educational Outcomes}

The implications of focusing broadly on the outcome of quality of life are relevant for implementing the reauthorized IDEA, research, and supports and services.

\section{Implications for Implementing IDEA}

Those involved in IDEA's implementation should take seriously the four IDEA goals and their meanings - equality of opportunity, full participation, independent living, and economic self-sufficiency-and guide and enable educators on how to implement them. This effort will not be easy, given the present federal, state, and local emphases on higher expectations for academic outcomes; but neither will it be fruitless, because academic outcomes are essentially a means to achieve the outcome (for all students) of a better quality of life; they are not ends in and of themselves. Table 1 aligns the IDEA goals and the eight quality of life domains recommended by The Special Interest Research Group on Quality of Life (2000). Table 1 shows congruence between the four IDEA goals and five of the quality of life domains. The remaining three quality of life domains-physical well-being, emotional wellbeing, and personal well-being - can be conceptualized as foundational skills that enable students with a disability to

\section{TABLE 1. Cross-Referencing of IDEA Goals and Quality of Life Domains}

\begin{tabular}{ll}
\hline \multicolumn{1}{c}{ IDEA goal } & Qualify of life domain \\
\hline 1. Equality of opportunity & - Rights \\
2. Full participation & - Social inclusion \\
& - Interpersonal relations \\
3. Independent living & - Self-determination \\
4. Economic self-sufficiency & - Material well-being \\
& - Physical well-being \\
& - Emotional well-being \\
& - Personal development
\end{tabular}

Note. $I D E A=$ Individuals with Disabilities Education Act Amendments of 1997. achieve IDEA's outcomes of equality of opportunity, full participation, independent living, and economic self-sufficiency.

To carry out a quality of life approach under the present IDEA and under any new legislation that retains the mandate of free, appropriate public education in the least restrictive, most general educational curriculum, the Office of Special Education Programs should ensure that state and local educational agencies develop policies, procedures, and practices that incorporate into the general education curriculum the four outcomes that encompass IDEA's intent and state and district assessments that hold stakeholders accountable for those outcomes. To do otherwise would simply validate the current narrow emphasis on accountability only for academic outcomes and remit the current emphasis on the No Child Left Behind Act to the unmemorable status of overpromised and underperformed law.

For example, OSEP should define these four outcomes relying on the definitions or concepts that are set out in ADA, DDABRA, and the Rehabilitation Act. OSEP should also fund state improvement grants and other research, demonstration, and technical assistance activities-all authorized under Part D of IDEA-related to curriculum, teacher competency, and measurement of student outcomes associated with the four IDEA goals.

To the same end, it is critical to ensure that Individualized Family Service Plans (IFSPS) and IEPs will reflect both family and student quality of life issues. Already, Congress requires the IFSP to reflect the family's "resources, priorities, and concerns" related to the development of their child and

a statement of the major outcomes expected to be achieved for . . . the family and the criteria, procedures, and timelines used to determine the degree to which progress toward achieving the outcomes is being made and whether modifications or revisions of the outcomes or services are necessary. (20 U.S.C. $\$ 1436(d)$ )

It would not be difficult for providers to address the more global issues of family quality of life, given that such a construct subsumes family resources, priorities, concerns, and outcomes and is measurable with psychometrically sound tools (A. P. Turnbull et al., 2001).

\section{Implications for Research}

Researchers who assert that the interventions they are investigating can enhance student outcomes could do their part by incorporating quality of life measurements and interventions into their research. Research related to self-determination, positive behavior support, and transition should follow its own rhetoric and incorporate quality of life measurements and interventions. Just as the construct of quality of life has profound policy implications (H. R. Turnbull \& Brunk, 1997; H. R. Turnbull \& Stowe, 2001), so Bailey et al. (1998) have 
proposed that the quality of life of families of children with disabilities is a "useful indicator of outcomes of policy initiatives" (p. 322). Although research on family quality of life is beginning to emerge (A. P. Turnbull, Brown, \& Turnbull, in press), there is a critical research need for further conceptualization and measurement related to family quality of life outcomes. It is essential to make a clear distinction between outcomes that are aimed at the individual quality of life of students with disabilities and outcomes for the family as a unit of support for the student.

\section{Implications for Services and Supports}

A quality of life paradigm has vast implications for special and general education services and supports in terms of achieving IDEA's goals. One of the greatest barriers, however, is the intense pressure on educators to align the curriculum with state and local standards that are too narrowly construed and to prepare students for high-stakes testing that reflects only academic achievement (Thurlow, 2000). There clearly needs to be a reconciliation between the emphasis placed on achievement in academic subjects and the accomplishment of quality of life results tied to IDEA's four goals. This reconciliation must occur at the policy level in order for educators to allocate their time and attention to the curriculum spanning the early intervention level through postsecondary education. Any curriculum should incorporate state-of-the-art content, standards, benchmarks, and indicators for quality of life domains.

\section{Summary AND CONCLUSION}

Despite the four outcomes that IDEA and other federal policy have established, there is gross inattention to all of them, except as they are addressed indirectly through the academic curriculum; indeed, as noted earlier, academic outcomes are unacceptable and too narrow: They do not encompass the global quality of life approach that IDEA implicitly justifies.

It is time to take stock and be serious-to take stock of what schools are doing and can do, and also to take stock of the outcomes for students with disabilities and how they can become more acceptable. Can educators and the public be satisfied with the current outcomes of students with disabilities? We think not. Can the field of education, working collaboratively with other human service fields and with families, do more? We think so.

Likewise, it is time to be serious about compliance with IDEA. Imagine the consequences if only $10 \%$ of all students ages 14 and over who are covered by IDEA were to file due process or Office of Civil Rights (OCR) complaints alleging that access to the general education curriculum is an insufficient guarantee of the outcomes that IDEA intends. The administrative hearing logjam would be humongous. And imagine the outcomes if hearing officers and OCR investiga- tors were to agree that mere access to the general education curriculum does not suffice and that IDEA really intends a far more robust curriculum to be available to students with disabilities.

We certainly do not advocate the administrative hearing process. Instead, we advocate that policymakers, education agency leaders, and researchers combine their forces to jointly address what schools are doing and can do under a different framework (the quality of life, four-outcome framework) to improve themselves and the lives of students with disabilities. It is within the power of policy leaders to ask for more and for educators to do better, and it is well beyond time for them and researchers to be serious about doing better. Anything less mocks the nation's policies and diminishes one of its greatest resources-educators and their students.

H. RUTHERFORD TURNBULL III, LIB/JD, LIM, ANN P. TURNBULL, EdD, and MICHAEL L. WEHMEYER, PhD, are professors of special education and codirectors (Turnbulls) and associate director (Wehmeyer) of the Beach Center on Disability, The University of Kansas. JIYEON PARK, $\mathrm{PhD}$, is an assistant professor of special education at Ewha University, Korea, and at the time of the research attributed to her was research associate at the Beach Center on Disability. Address: $\mathrm{H}$. Rutherford Turnbull III, Beach Center on Disability, 3136 Haworth Hall, 1200 Sunnyside Ave., University of Kansas, Lawrence, KS 66045-7354.

\section{REFERENCES}

Americans with Disabilities Act of 1990, 42 U.S.C. $\$ 12000$ et seq.

Becker, M., Diamond, R., \& Sainfort, F. (1993). A new patient-focused index for measuring quality of life in persons with severe and persistent mental illness. Quality of Life Research, 2, 239-251.

Blackorby, J., \& Wagner, M. (1996, March-April). Longitudinal post-school outcomes for youth with disabilities: Findings from the National Longitudinal Transition Study. Exceptional Children, 62, 399-413.

Borthwick-Duffy, S. A. (1996). Evaluation and measurement of quality of life: Special considerations for persons with mental retardation. In $R . L$. Schalock (Ed.). Quality of life: Vol. 1. Conceptualization and measurement (pp. 105-119). Washington, DC: American Association on Mental Retardation.

Bradley, V., \& Knoll, J. (1990). Shifting paradigms in services to people with developmental disabilities. Cambridge, MA: Human Services Research Institute.

Browning, P. L., Dunn, C., Rabren, K., \& Whetstone, M. (1995). Post-school outcomes for students with disabilities: A U.S. synopsis. Issues in Special Education and Rehabilitation, 10(1), 31-37.

Carr. E. G., Horner, R. H., Turnbull, A. P., Marquis, J. G., McLaughlin, D. M., McAtee, M. L., et al. (1999). Positive behavior support for people with developmental disabilities: A research synthesis. Washington, DC: American Association on Mental Retardation.

Conroy, J., \& Feinstein, C. (1990). Measuring quality of life: Where have we been, where are we going? In R. Schalock (Ed.), Quality of life: Perspectives and issues (pp. 227-234). Washington, DC: American Association on Mental Retardation.

Cummins, R. A. (1997). Assessing quality of life. In R. I. Brown (Ed.), Assessing quality of life for people with disabilities: Models, research and practice (pp. 116-150). Cheltenham, UK: Stanley Thornes.

Cummins, R. A., McCabe, M. P., Romeo, Y., \& Gullone, E. (1994). The Comprehensive Quality of Life Scale: Instrument development and psychometric evaluation on tertiary staff and students. Educational and Psychological Measurement, 54, 372-382.

Developmental Disabilities Assistance and Bill of Rights Act, 42 U.S.C. $\S 15001$ et seq. 
Edgerton, R. (1990). Quality of life from a longitudinal research perspective. In R. Schalock \& M. J. Bogale (Eds.), Quality of life: Perspectives and issues (pp. 149-160). Washington, DC: American Association on Mental Retardation.

Fabian. E. S., Lent, R. L., \& Willis, S. P. (1998). Predicting work transition outcomes for students with disabilities: Implications for counselors. Journal of Counseling and Development, 76, 311-315.

Felce, D. (1997). Defining and applying the concept of quality of life. Journal of Intellectual Disability Research, 4l, 126-135.

Ferrans, C. E., \& Powers, M. J. (1985). Quality of life index: Development and psychometric properties. American Nursing Science, 8(1), 15-24.

Finn, C. E., Rotherman, A. J., \& Hokanson, C. R. (2001). Rethinking special education for a new century. Washington, DC: Thomas B. Fordham Foundation and the Progressive Policy Institute.

Gill, T. M., \& Feinstein, A. R. (1994). A critical appraisal of the quality of quality-of-life measurements. The Journal of the American Medical Association, 272, 619-626.

Halpern. A. S. (1993). Quality of life as a conceptual framework for evaluating transition outcomes. Exceptional Children, 59, 486-498.

Hatton. C. (1998). Whose quality of life is it anyway?: Some problems with the emerging quality of life consensus. Mental Retardation, 36, 104115 .

Horner, R. H., Koegel, R. L., Carr, E. G., Sailor, W., Anderson, J., Albin, W. R., et al. (1990). Toward a technology of "nonaversive" behavioral support. The Journal of the Association for Persons with Severe Handicaps, $15,125-132$.

Hughes, C. \& Hwang, B. (1996). Attempts to conceptualize and measure quality of life. In R. L. Schalock (Ed.), Quality of life: Vol. 1. Conceptualization and measurement (pp. 51-61). Washington. DC: American Association on Mental Retardation.

Individuals with Disabilities Education Act Amendments of 1997, P.L. 10517, 20 U.S.C. $\$ 1400$ et seq.

Keith, K. D., \& Schalock, R. L. (1994). The measurement of quality of life in adolescence: The quality of student life questionnaire. American Journal of Family Therapy, 22(1), 83-87.

Lehman, A. F. (1988). A quality of life interview for the chronically mentally ill. Evaluation and Program Planning, 11, 51-62.

National Center for Education Statistics. (2000). Dropout rates in the United States: 1998. Washington, DC: U.S. Department of Education, Office of Educational Research and Improvement.

O'Boyle, C. A. (1997). Quality of life assessment: A paradigm shift in healthcare? The Irish Journal of Psychology, 18, 51-66.

President's Commission on Excellence in Special Education. (2002). A new era: Revitalizing special education for children and their families. Washington, DC: U.S. Department of Education.

Ouellette-Kuntz, H., \& McCreary, B. D. (1996). Quality of life assessment for persons with severe developmental disabilities. In R. Renwick, I. Brown, \& M. Nagler (Eds.), Quality of life in health promotion and rehabilitation (pp. 268-278). Thousand Oaks, CA: Sage.

Rehabilitation Act of 1973, 29 U.S.C. 794

Ross, J. K. (1996). Social security: Disability programs lag in promoting return to work (Testimony Before the Special Committee on Aging. U.S. Senate, GAO/T-HEHS-96-147). Washington, DC: U.S. General Accounting Office.

Schalock, R. L. (1996). Reconsidering the conceptualization and measurement of quality of life. In R. L. Schalock (Ed.), Quality of life: Vol. I. Conceptualization and measurement (pp. 123-139). Washington, DC: American Association on Mental Retardation.

Schalock. R. (2000). Three decades of quality of life: Mental retardation in the 21 st century. In M. L. Wehmeyer \& J. R. Patton (Eds.), Mental retardation in the year 2000 (pp. 335-355). Austin, TX: PRO-ED.

Schalock, R. L., Keith, K. D., Hoffman, K., \& Karen, O. C. (1989), Quality of life, its measurement and use in human service programs. Mental Retardation, 27(1), 25-31.

Stainback, W., \& Stainback, S. (1989). Using qualitative data collection procedures to investigate supported education issues. Journal of the Association for Persons with Severe Disabilities, 14, 271-277.
Stark, J., \& Goldsbury, T. (1990). Quality of life from childhood to adulthood. In R. Schalock \& M. J. Bogale (Eds.), Quality of life: Perspectives and issues (pp. 71-84). Washington, DC: American Association on Mental Retardation.

Taylor, S., \& Bogdan, R. (1990). Quality of life and the individual's perspective. In R. L. Schalock (Ed.), Quality of life: Perspectives and issues (pp. 27-40). Washington, DC: American Association on Mental Retardation.

Testa, M. A., \& Simonson, D. G. (1996). Assessment of quality-of-life outcomes. The New England Journal of Medicine. 334, 835-840.

Thurlow, M. L. (2000). Standards-based reform and students with disabilities: Reflections on a decade of change. Focus on Exceptional Children, 33(3). 1-16.

Timmons, V. (1993). Quality of life of teenagers with special needs. Unpublished doctoral dissertation, The University of Calgary, Canada.

Turnbull. A., Brown. I., \& Turnbull, R. (in press). Family quality of life: International perspectives. Washington. DC: American Association on Mental Retardation.

Turnbull, A. P., \& Turnbull, H. R. (1985). Developing independence. Journal of Adolescient Health Care, 6(2), 108.

Turnbull, A., Turnbull, H. R., Poston, D., Beegle, G., Blue-Banning, M., Dieh1, K., et al. (in press). Enhancing quality of life of families of children and youth with disabilities in the United States. In A. Turnbull, I. Brown, \& R. Turnbull (Eds.). Family quality of life: International perspectives. Washington. DC: American Association on Mental Retardation.

Turnbull, H. R., Beegle, G., \& Stowe, M. S. (2001). The core concepts of disability policy affecting families who have children with disabilities. Journal of Disability Policy Studies, 12, 133-143.

Tumbull, H. R., \& Brunk, G. (1990, 1997). Quality of life and public policy. In R. I. Schalock (Ed.), Quality of life: Application to persons with disabilities. Washington, DC: American Association on Mental Retardation.

Turnbull, H. R.; \& Stowe, M. J. (2001). A taxonomy for organizing the core concepts according to their underlying principles. Journal of Disability Policy Studies, 12, 177-197.

Turnbull, H. R., Wilcox, B. L., Stowe, M. J., \& Umbarger, G. T. (2001). Matrix of federal statutes and federal and state court decisions reflecting the core concepts of disability policy. Journal of Disability Policy Studies, $12,144-176$.

Wehmeyer, M. L. (1996). Self-determination as an educational outcome: Why is it important to children, youth, and adults with disabilities? In D. J. Sands \& M. L. Wehmeyer (Eds.), Self-determination across the life span: Independence and choice for people with disabilities (pp. 17-36). Baltimore: Brookes.

Wehmeyer, M. L., Lattin, D., \& Agran, M. (2001). Promoting access to the general curriculum for students with mental retardation: A decisionmaking model. Education and Training in Mental Retardation and Developmental Disabilities, 36, 329-344.

Wehmeyer, M. L., Sands, D. J., Knowlton, H. B., \& Kozleski, E. B. (2002). Teaching students with mental retardation: Providing access to the general curriculum. Baltimore: Brookes.

Wehmeyer, M. L., \& Schalock, R. L. (2001). Self-determination and quality of life: Implications for special education services and supports. Focus on Exceptional Children, 33(8), 1-16.

Wehmeyer, M.; \& Schwartz, M. (1998). The relationship between selfdetermination and quality of life for adults with mental retardation. Education and Training in Mental Retardation and Developmental Disabilities, 33(1), 3-12.

Ysseldyke, J., Krentz, J., Elliott, J., Thurlow, M., Erickson, R., \& Moore, M. (1998). NCEO framework for educational accountability. Minneapolis: University of Minnesota, National Center on Educational Outcomes.

Received April 29, 2002

Revision received September 8,2002 Final acceptance September 17, 2002 